\title{
Flow Field Calculation and Dynamic Characteristic Analysis of Spherical Hybrid Gas Bearings Based on Passive Grid
}

\author{
Chenhui Jia ${ }^{1}$, Zhiwu Cui ${ }^{1 *}$, Shijun $\mathrm{Guo}^{2}$, Ming Qiu ${ }^{1}$, Wensuo $\mathrm{Ma}^{3}$ \\ ${ }^{1}$ School of Mechatronics Engineering, Henan University of Science and Technology, \\ Luoyang, Henan; ${ }^{2}$ Cranfield University, School of Aerospace, Transport and \\ Manufacturing, England; ${ }^{3}$ Machinery and equipment advanced manufacturing \\ collaborative innovation center in Henan Province, China
}

Corresponding author's email: ccuizhiwu@163.com

\begin{abstract}
In order to research the spherical spiral groove hybrid gas bearings, the Realizable k- $\varepsilon$ turbulence model of gas film was established based on FLUENT. The simulation calculation method of 6-degrees of freedom (DOF) passive grid was used, which can simulate the lubrication characteristics of the gas film transient flow field accurately. And the gas film pressure distribution and dynamic characteristic coefficients are numerically calculated. The dynamic and static pressure coupling effects of the gas flow field was analyzed and the axis motion trajectory was simulated. The effect of rotation speed, gas supply pressure and tangential angle on the dynamic characteristic coefficients during bearing operation were analyzed. And the stability of the gas bearing was studied. The conclusion from the analysis shows that different rotation speed and gas supply pressure will change the pressure distribution of the gas bearing during the operation. The dynamic characteristics of the gas film can be changed by reasonably optimizing the operation parameters, which can change the whirl characteristics of the gas film and improve the stability. Through calculation and analysis, the tangential angle is selected between $55^{\circ}$ and $60^{\circ}$, both to ensure that the gas film has a high stiffness, while also can obtain the larger damping. The simulation results and the experimental results are compared and analyzed to verify the correctness and effectiveness of the simulation method. At the same time, the research of this paper provided a theoretical basis for optimizing the bearing structure and operating parameters, improving the dynamic characteristics of gas bearings and improving the operation stability.
\end{abstract}

Keywords: Spherical hybrid gas bearings; 6-degrees of freedom passive grid; Gas film pressure distribution, Dynamic and static pressure coupling effects; Dynamic characteristic coefficients; Stability 


\section{Introduction}

Gas bearing is a new type of sliding bearing with viscous gas as the main lubricating medium, which have obvious advantages in the fields of high speed, high precision, low friction and extreme working conditions ${ }^{1-3}$. The gas film with a certain bearing capacity was formed between the rotor and the stator when the bearing rotates at high speed, and the transient flow characteristics are very complex. Hybrid gas bearings has the nonlinear coupling effect of static pressure and dynamic pressure. The phenomenon of whirl instability and gas film oscillation occurs at high speed, which lead to the failure of bearings and restrict the wide application of gas bearings ${ }^{4,5}$. The dynamic characteristics of the gas film reflect the variation law of the gas film force when the journal deviates from the static equilibrium position and the displacement motion in the vicinity, which has very complex non-linear and stochastic characteristics. The random variation of the gas film dynamic characteristics will cause the change of the gas film motion state. It is expressed as a random change of the stability of the gas film, and directly affects the motion state of the bearing rotor $^{6-8}$. Therefore, the calculation and analysis of dynamic characteristics of bearing gas film is the key to study the stability of gas bearing ${ }^{9}$.

At present most scholars have studied the stability of hybrid gas bearings basically using experimental and theoretical ${ }^{10-12}$. The theoretical calculation is basically based on the Reynolds lubrication equation. The dynamic characteristic coefficients were obtained by solving simultaneously the linear equations, and the stability of the bearing was analyzed. Because the Reynolds equation can not accurately reflect the nonlinear coupling relation between the circumferential inertial effect of high speed airflow, the circumferential dynamic pressure effect of the journal and the static pressure diffusion effect, and the effect on the three-dimensional flow field characteristics. Therefore, the calculation of the stiffness and damping of the gas film deviates from the true value and the error is large. The real motion state of the bearing can not be accurately analyzed ${ }^{13,14}$. However, testing the dynamic characteristic coefficients of the bearing ask for the rigorous experimental conditions. In the test process, various external factors inevitably interfere with the test, which makes the test result have certain error.

In this paper, the Realizable $\mathrm{k}-\varepsilon$ turbulence model of the spherical spiral groove hybrid gas bearings gas film was established based on FLUENT. The pressure 
distribution on the grid point of the gas film was numerically calculated by using 6 DOF passive grid. Simulating the complex gas flow in the transient flow field of the gas film. The dynamic and static pressure coupling effect of the gas flow field was analyzed. The dynamic trajectory of axis was simulated and the dynamic characteristic coefficients were calculated. The influence law of rotation speed, gas supply pressure and tangential angle on the dynamic characteristic coefficients was analyzed during bearing movement. The mechanical mechanism of gas bearing stability was studied. The validity and feasibility of theoretical calculation and simulation analysis were verified through experimental analysis. The research provides the theoretical foundation for optimizing the structure and operation parameters of hybrid gas bearings, improving dynamic characteristics and improving operation stability.

\section{Calculation model of gas bearing}

\subsection{Three - dimensional model of bearing gas film}

This article takes the hybrid gas bearings as the research object, and the bearing consists of two portions of the rotor and the stator. There is a certain number of air holes on the stator, the rotor is provided with spiral grooves, the spiral groove by the groove area and the platform area, as shown in figure 1. On the one hand after the introduction of external high pressure gas by restrictor to bearing clearance, static gas film is formed and generating in static bearing capacity. On the other hand the wedging effect between rotor and stator is produced when the bearing rotates at high speed, dynamic pressure gas film is formed and generating in dynamic bearing capacity. The transient flow field characteristics of the gas film reflect the dynamic bearing performance and stability of the bearing during the operation. 


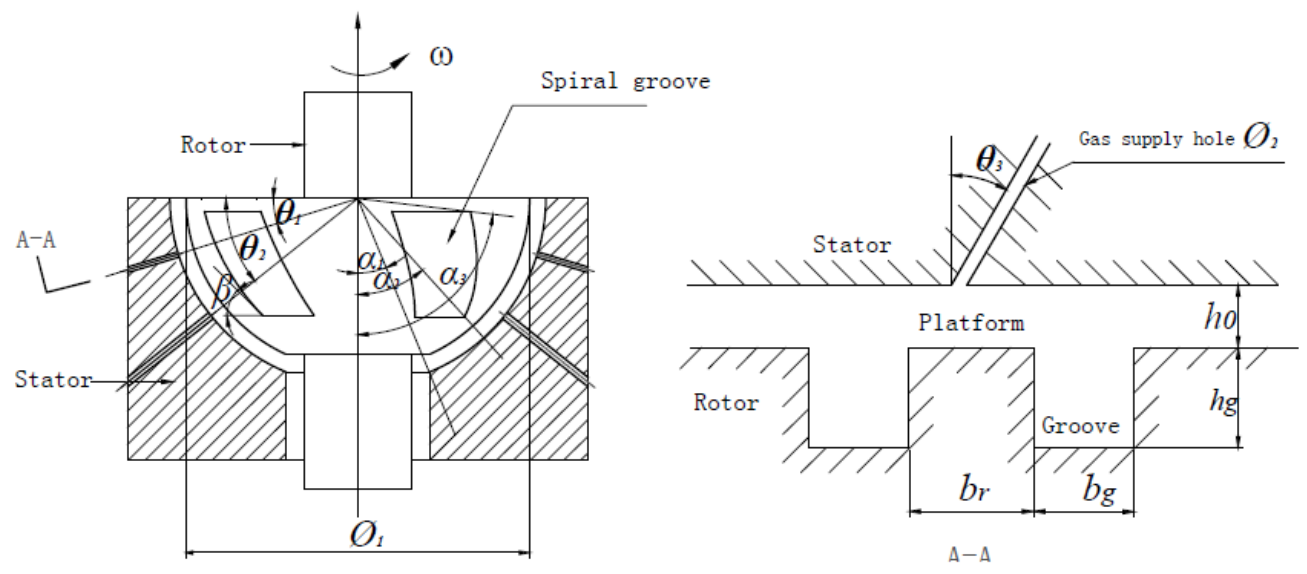

Figure 1. Spherical spiral groove hybrid gas bearings profile diagram

In Figure $1, \beta$ is the helix angle, $\phi_{1}$ is the diameter of the bearing, $\phi_{2}$ is the diameter of the gas supply hole, $\omega$ is the rotation speed, $b_{r}$ is the table width, $b_{g}$ is the groove width, $h_{g}$ is the groove area clearance, $h_{0}$ is the average gas film thickness, groove depth ratio $\bar{h}=\left(h_{0}+h_{g}\right) / h_{0}$, groove width ratio $\bar{b}=b_{g} /\left(b_{r}+b_{g}\right), \theta$ for the gas supply hole angle, $\alpha_{1} 、 \alpha_{2} 、 \alpha_{3}$ for the wrap angle, $\theta_{1} 、 \theta_{2}$ is the axial supply hole angle, $\theta_{3}$ is the tangential angle with reversely tangential gas supply holes.

Using the space spherical coordinate system, the model structure parameters $\beta=70^{\circ}, \mathrm{R}=7.5 \mathrm{~mm}$. Based on the spherical conformal space coordinate system, the spherical helix equations (1) were established in Pro / E, and the spherical helix was obtained, as shown in figure 2.

$$
\left\{\begin{array}{l}
R=7.5 \\
\theta=\varphi \times \tan 70^{\circ}+90 \\
\varphi=360 \times t
\end{array}\right.
$$

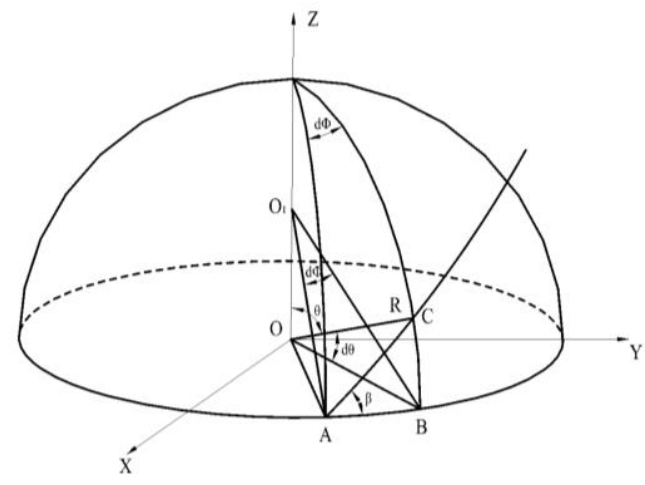


Figure 2. Spherical isometric space relation diagram

The three-dimensional model of the gas film of the bearing was established by using the space spherical coordinate system, the helix and the structure parameters of the bearing. The three-dimensional gas film model of the hybrid gas bearings was established by using Pro/E. Change the default precision in Pro / E to $1 \mu \mathrm{m}$ to meet the high accuracy requirements of the model.

Model structure parameters: $\phi_{1}=15 \mathrm{~mm}, \phi_{2}=0.2 \mathrm{~mm}, \beta=70^{\circ}, h_{0}=20 \mu \mathrm{m}$, $\alpha_{1}=26^{\circ}, \alpha_{2}=32^{\circ}, \alpha_{3}=85^{\circ}$, dimensionless eccentricity $\varepsilon=0.3$, groove width ratio $\bar{b}=0.4$, groove depth ratio $\bar{h}=3.6$. The three-dimensional model of the gas film is shown in figure 3 .

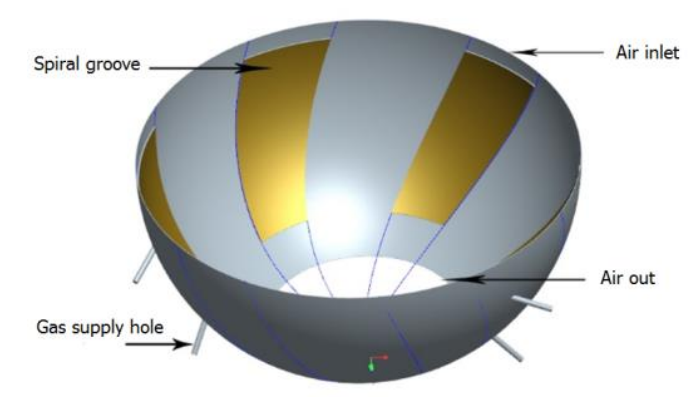

Figure 3. Spherical spiral groove hybrid gas bearings gas film three-dimensional model

\subsection{Governing equation}

In this paper, the lubrication flow field in the gas bearing can be described by the mass conservation equation and the momentum conservation equation.

(1) Mass conservation equation

$$
\frac{\partial \rho}{\partial t}+\operatorname{div}(\rho u)=0
$$

Where $\rho$ is the air density; $t$ is the flow time; $\operatorname{div}(\rho u)$ is the divergence of the velocity vector $u$.

(2) The momentum conservation equation 
Where $\mu$ is the dynamic viscosity; $S_{u} 、 S_{v} 、 S_{w}$ is momentum conservation equation of the generalized source term; $u 、 v 、 w$ is the velocity vector on the $\mathrm{x}, \mathrm{y}, \mathrm{z}$ direction of the velocity components.

When the transient flow field of the bearing gas film is simulated, the $6 \mathrm{DOF}$ solver uses the force and moments of the rotor to compute the translational and angular motion of the center of gravity of the rotor, thus obtaining the motion trajectory of the bearing rotor.

The governing equation for the translational motion of the center of gravity is solved for in the inertial coordinate system:

$$
\dot{\vec{v}}_{G}=\frac{1}{m} \sum \vec{f}_{G}
$$

Where $\dot{\vec{v}}_{G}$ is the translational motion of the center of gravity, $m$ is the mass, and $\vec{f}_{G}$ is the force vector due to gravity.

The angular motion of the object $\dot{\vec{\omega}}_{B}$ is more easily computed using body coordinates:

$$
\dot{\vec{\omega}}_{B}=L^{-1}\left(\sum \vec{M}_{B}-\vec{\omega}_{B} \times L \vec{\omega}_{B}\right)
$$

Where $L$ is the inertia tensor, $\vec{M}_{B}$ is the moment vector of the body, and $\vec{\omega}_{B}$ is the rigid body angular velocity vector.

After the angular and the translational accelerations are computed from Equation (4) and Equation (5), the rates are derived by numerical integration. The angular and translational velocities are used in the dynamic mesh calculations to update the rotor position. 


\subsection{Finite element mesh model}

The gas bearing is meshed by FLUENT pretreatment software ICEM CFD. Due to the large difference in size of the hybrid gas bearings in the three directions of the space, and the gas film thickness is generally within a few tens of microns. It is more reasonable to use structured grid partition method, which can improve the precision of numerical calculation and save calculation time, and reduce the probability of the negative volume of the grid. After comparing and analyzing the calculation results of the calculation model under different grid densities. It is found that the different grid numbers in the gas supply hole and the spiral groove lead to the difference of the calculation results. The grid was properly encrypted in the position of the gas supply hole and the spiral groove, O-type grids were used in the gas supply holes. The grid of the gas film is shown in figure 4.
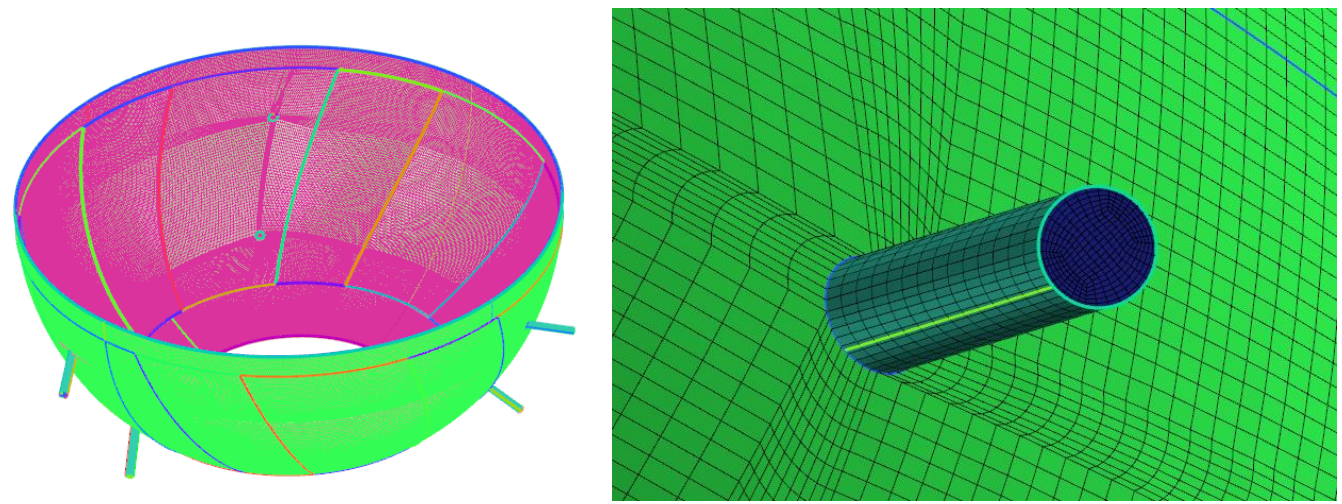

Figure 4. Finite element calculation model

\section{Numerical calculation of flow field}

\subsection{FLUENT calculation model and model hypothesis}

\subsubsection{The flow Realizable $k-\varepsilon$ model}

In the dynamic calculation of the model, FLUENT mainly has active and passive grid two ways to control the model of the grid deformation. The active dynamic grid is usually used in the boundary motion law and the motion state is known. The boundary motion trajectory program is called to simulate the boundary motion, and the transient flow field characteristics of the model are calculated. The passive dynamic grid is usually used for the boundary motion and the motion state is unknown. It is often 
necessary to obtain the boundary motion by calculating the force or torque on the boundary. The hybrid gas bearings motion state is unknown, it is mainly by the bearing structure parameters, rotation speed, gas supply pressure, external load and other factors. Therefore, the passive grid is more appropriate to calculate the dynamic characteristics of the bearing, and it can also simulate the motion characteristics of the bearing gas film more realistically.

The k- $\varepsilon$ model of the turbulence model is a two-equation model, which contains the transport equation for the turbulent kinetic energy $\mathrm{k}$ and the equation for the turbulent dissipation rate $\varepsilon$. The k- $\varepsilon$ model is also divided into standard k- $\varepsilon$ model, RNG $\mathrm{k}-\varepsilon$ model, and Realizable k- $\varepsilon$ model. The Realizable k- $\varepsilon$ model is applied to the flow of higher mainstream shear rate and larger curvature. It can achieve better calculation results for the swirling flow, boundary layer flow with strong pressure gradient and complex secondary flow. Hybrid gas bearings with a smaller size, the speed can be up to tens of thousands or even hundreds of thousands during the operation. When the bearing rotates at high speed, the motion of the gas film will appear as whirl and cyclone. This model can well simulate the cyclone phenomenon at the gas supply hole. So the Realizable k- $\varepsilon$ turbulence model is adopted in this paper.

\subsubsection{Model hypothesis}

The lubrication analysis model of the spherical helical groove hybrid gas bearings which reflects the pressure field and velocity field distribution, dynamic bearing characteristics and lubrication characteristics of the gas film in the bearing clearance. In the calculation of the fluid has the following assumptions: (1) The lubricating medium is Newton fluid, and the gas viscosity coefficient is constant; (2) There is no heat exchange between the gas and the wall, and the thermal deformation of the bearing and journal is not considered during the rotation; (3) In the direction perpendicular to the thickness of the gas film, the velocity change is neglected, that is the pressure does not change along the gas film thickness; (4) The gas does not have relative sliding on the shaft and bearing surfaces; (5) The wall is assumed to be smooth, without considering the influence of wall roughness and slip boundary.

\subsubsection{Boundary conditions}

The boundary conditions for flow field calculations are used for three boundary 
conditions for inlet, outlet and wall. (1)The gas supply hole and large end of the gas bearing is the pressure boundary condition, the total inlet pressure is given. (2)The small end of the gas bearing is also the pressure boundary condition, and the pressure is set as ambient atmospheric pressure according to the actual situation. (3)The remaining boundary of the bearing is set as a wall surface, and there is no relative sliding between the wall surfaces. The inner wall surface of the gas film is set as a rotating rigid wall, and the outer wall surface of the gas film and the wall surface of the gas supply holes are set as fixed wall surfaces.

\subsection{Steady-state solution calculation}

After introducing the gas bearing grid into FLUENT, the 3D pressure base implicit solver is selected, and the boundary conditions of the flow field calculation are set up. PISO algorithm is used in the pressure and velocity coupling, and the algorithm is based on SIMPLE algorithm. The difference between the two is that after a given pressure to solve the momentum equation and the continuous equation, the PISO algorithm needs to correct the pressure and velocity equations twice, so that the pressure and velocity reach the second and third order precision of the moment. Due to the influence of the high speed rotation of the journal on the flow field, the interpolation discrete format of the pressure equation chooses PRESTO. The residual difference of all equations is less than 0.0001 , and the flow rate of the inlet and outlet is monitored during the calculation. And the calculation is convergent when the numerical value is basically equal.

The steady-state calculation is based on the given structure parameters and operating parameters. It is assumed that the gas bearing can operate stably under given radial and axial eccentric conditions, and through the FLUENT simulates the flow field in the gas film thickness. The pressure field and velocity field distribution at each grid point were calculated numerically, and the steady gas film pressure distribution and the steady state bearing performance are obtained. The steady-state calculation flow chart as shown in figure 5 : 


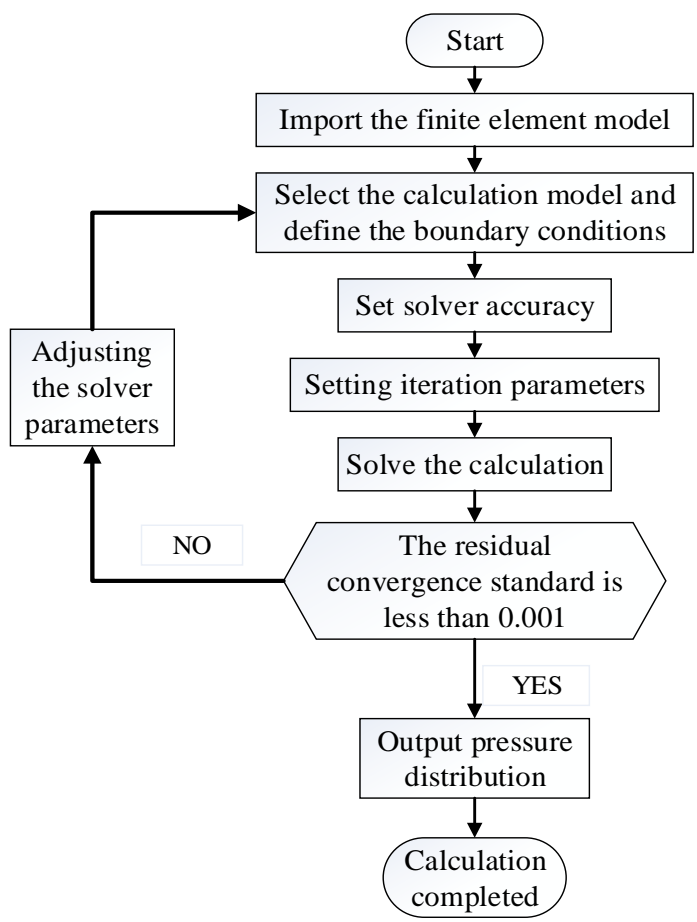

Figure 5. Steady-state simulation calculation flow chart

\subsection{Transient calculation}

The gas bearing is based on the given structure parameters and operating parameters, and through the FLUENT simulates the flow field in the gas film thickness. The pressure distribution at each grid point of gas film are calculated numerically, and the dynamic characteristic coefficients of the bearing are obtained. The dynamic calculation flow chart as shown in Figure 6: 
Figure 6. Dynamic simulation calculation flow chart

First, write a 6 DOF dynamic program. The meaning of 6 DOF is 6 degrees of freedom, with three translation motions and three rotational motions. The $6 \mathrm{DOF}$ program can limit or release the degree of freedom required for the rotor during transient calculations. The quality and moment of inertia of the rotor can be obtained during modeling, while the 6 DOF program is programmed according to the UDF manual. Because the opposed hemispherical bearing is used in the test, the axial translation is cancelled, so the Z-direction translation freedom is limited in the simulation calculation.

In dynamic calculations, select a period of time during the simulation and output the force, velocity, and displacement of the gas film at each time step. Since the time step is very short, the rotor running state and the film force change are small in the process of output data for 5 consecutive times. So the calculation of the change of force, velocity and displacement starts from the sixth groups, and then the dynamic stiffness damping coefficient of the gas film is calculated by Equation (6). According to the above method, the Matlab program is compiled, and the rolling iteration method is used to process and calculate the data. Finally, obtain the average value to obtain the dynamic stiffness damping coefficient of the bearing. 


$$
\left\{\begin{array}{l}
\Delta F_{x}=k_{x x} \cdot \Delta x \\
\Delta F_{x}=k_{x y} \cdot \Delta y \\
\Delta F_{y}=k_{y y} \cdot \Delta y \\
\Delta F_{y}=k_{y x} \cdot \Delta x
\end{array},\left\{\begin{array}{l}
\Delta F_{x}=b_{x x} \cdot \Delta v_{x} \\
\Delta F_{x}=b_{x y} \cdot \Delta v_{y} \\
\Delta F_{y}=b_{y y} \cdot \Delta v_{y} \\
\Delta F_{y}=b_{y x} \cdot \Delta v_{x}
\end{array}\right.\right.
$$

Where $\Delta F_{x}, \Delta F_{y}$ is the variation of bearings gas film force between at two time points, $k_{x x} 、 k_{y y}$ is the direct stiffness coefficients, $k_{x y} 、 k_{y x}$ is the cross stiffness coefficients, $b_{x x} 、 b_{y y}$ is the direct damping coefficients, $b_{x y}, b_{y x}$ is the cross damping coefficients, $\Delta x, \Delta y$ are displacement variations of bearings in the $\mathrm{X}$ and $\mathrm{Y}$ directions respectively, $\Delta v_{x}, \Delta \mathrm{v}_{y}$ are the velocity variations of the bearing in $\mathrm{X}$ and $\mathrm{Y}$ direction respectively.

\section{Pressure distribution and dynamic and static pressure coupling effects}

The gas film pressure distribution of the hybrid gas bearings is mainly influenced by the operation parameters and the structure parameters of the bearings. The influence of gas supply pressure and rotation speed on the stability of bearings was studied by the pressure distribution characteristics of the bearings gas film ${ }^{15-17}$.

Pressure nephogram of three dimensional gas film pressure of hybrid gas bearings when gas supply pressure is $0.2 \mathrm{MPa}$ and rotation speed is $30000 \mathrm{r} / \mathrm{min}$.
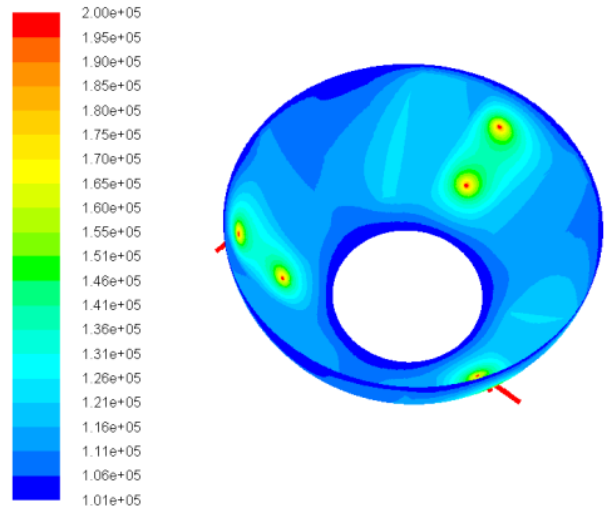

Figure 7. Gas film pressure nephogram of bearing

As can be seen from Figure 7, due to the existence of bearing eccentricity, the gas flow has a wedging effect when the bearings is running. And the convergence region and the divergence region are formed in the gas film thickness. The gas film pressure in the convergence region is gradually increased, the gas film pressure is the 
largest in the area near the smallest gas film thickness. The gas film pressure in the divergence region is decreasing rapidly. The gas film pressure is abrupt change at the junction of the groove table of the bearings spiral groove. The gas film pressure at the junction of the side of the increased sharply, the other side plummeted. The dynamic pressure effect is significantly enhanced when the bearing rotation speed is gradually increased.

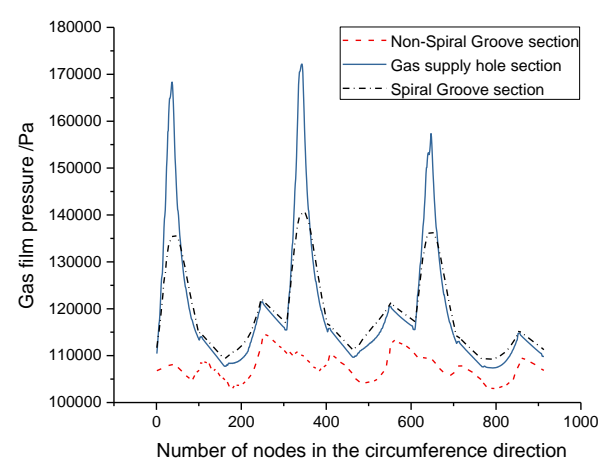

a.

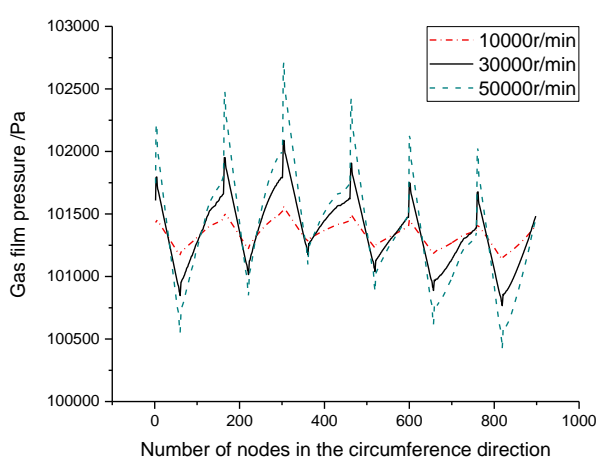

b.

Figure 8. Gas film circumferential pressure distribution

Figure 8 shows the pressure distribution of the gas film on the different circumference sections of the bearings when the rotation speed is $30000 \mathrm{r} / \mathrm{min}$; Figure $8 \mathrm{~b}$ is the distribution of gas film pressure at different rotation speeds of the spiral groove section of the bearing when the gas supply pressure is low. It can be seen from the figure that the static pressure effect is obviously enhanced near the bearing supply holes and the dynamic pressure effect appears near the spiral groove. The pressure of gas film increases with the increase of rotation speed, and the dynamic and static pressure coupling effects was formed to bear the bearing capacity of gas film. And makes the pressure distribution in the circumferential direction more uniform, load distribution more reasonable. The dynamic pressure effect is greatly influenced by the rotation speed. The higher the speed, the greater the eccentricity, which makes the dynamic pressure effect more obvious. In order to obtain larger bearing capacity, gas bearings need to increase the spiral groove and other structures, increase eccentricity, reduce the average gas film thickness to enhance the dynamic pressure effect. However, the gas film force which leads to the gas film whirl is increased, and the typical whirl phenomenon is caused. When the whirl is larger, the amplitude increases, which is the important reason of rotor instability. Hybrid gas bearings can enhance the static pressure effect by increasing the gas supply pressure to improve the bearing performance while 
maintaining reasonable dynamic pressure effect. While greatly improving the bearing capacity, it is also more conducive to better guarantee the stability under large load.

When the rotation speed is high, the bearing capacity generated by static pressure effect of bearings increases slowly with the increase of the gas supply pressure. At this time, the dynamic pressure effect increases greatly due to the high rotation speed, which makes the static pressure and dynamic pressure coupling effect bearing capacity stronger. Therefore, dynamic and static pressure coupling effects can complement each other better, which can not only enhance the bearing performance of the gas film, but also optimize the dynamic characteristics. It can effectively restrain the generation of whirl and oscillation, and improve the stability of high speed operation.

\section{Axis dynamic trajectory simulation}

During the operation of the hybrid gas bearings, the different axis trajectory can reflect the motion state and the fault information of the bearing. The stability of the bearing can be judged by the convergence and divergence of the bearing axis trajectory ${ }^{18-20}$. There are many factors that affect the axial trajectory of the hybrid gas bearings, such as gas supply pressure, rotor speed, bearing structure parameters, external disturbances and so on. In this paper, the influence of rotation speed on the axial trajectory of hybrid gas bearings was studied. Through simulation of bearing axis trajectory diagram and spectrogram, the influence on gas film stability was analyzed.
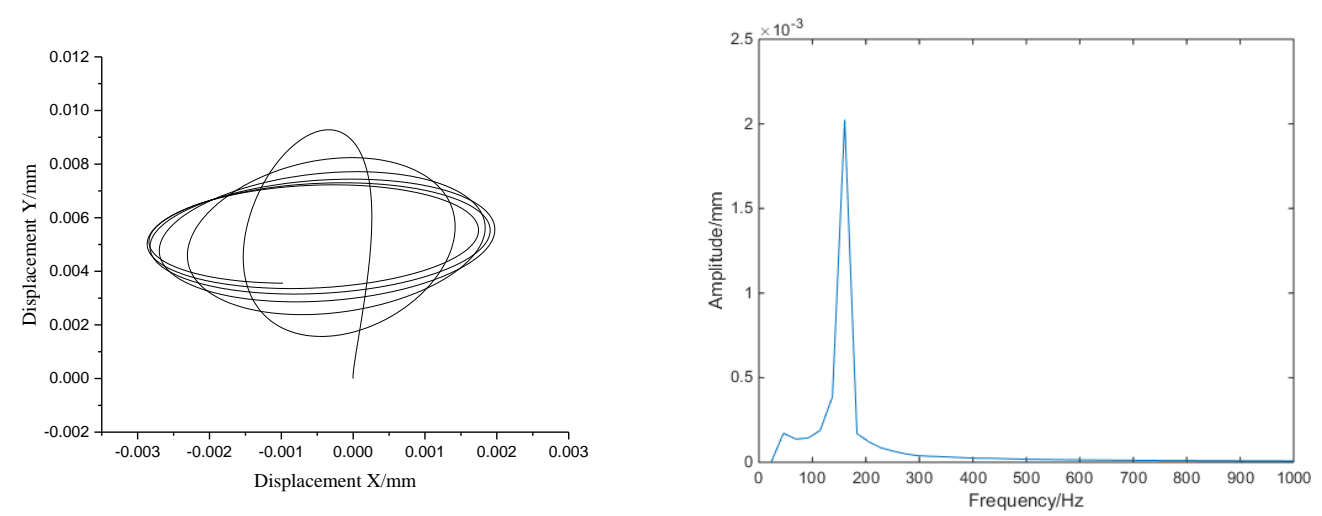

Figure 9. 10000r/min axis trajectory diagram and spectrogram 

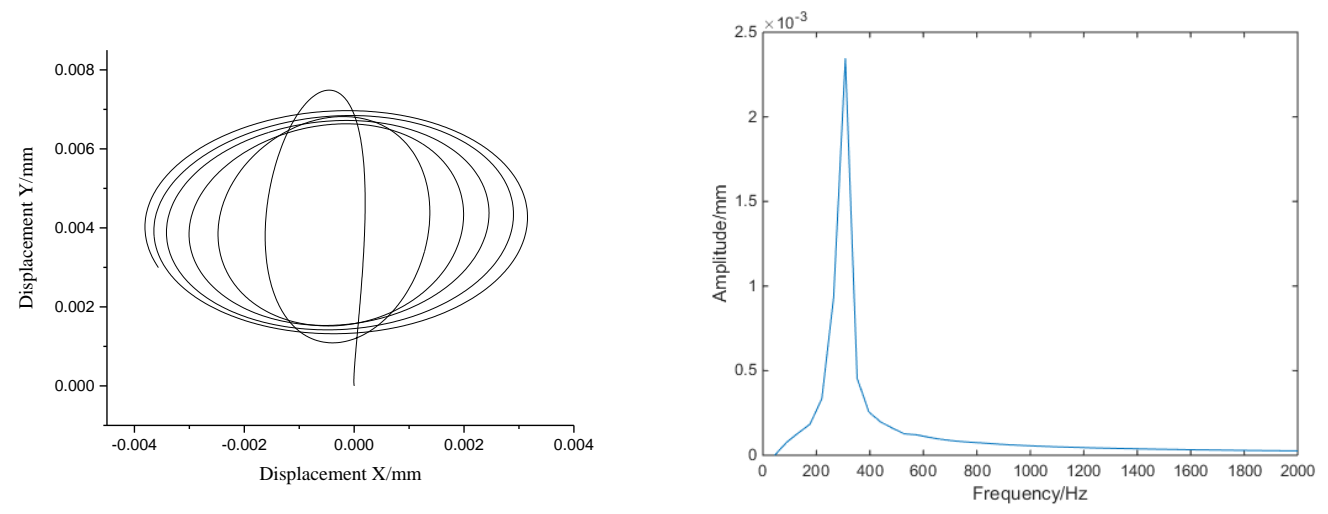

Figure 10.17500r/min axis trajectory diagram and spectrogram
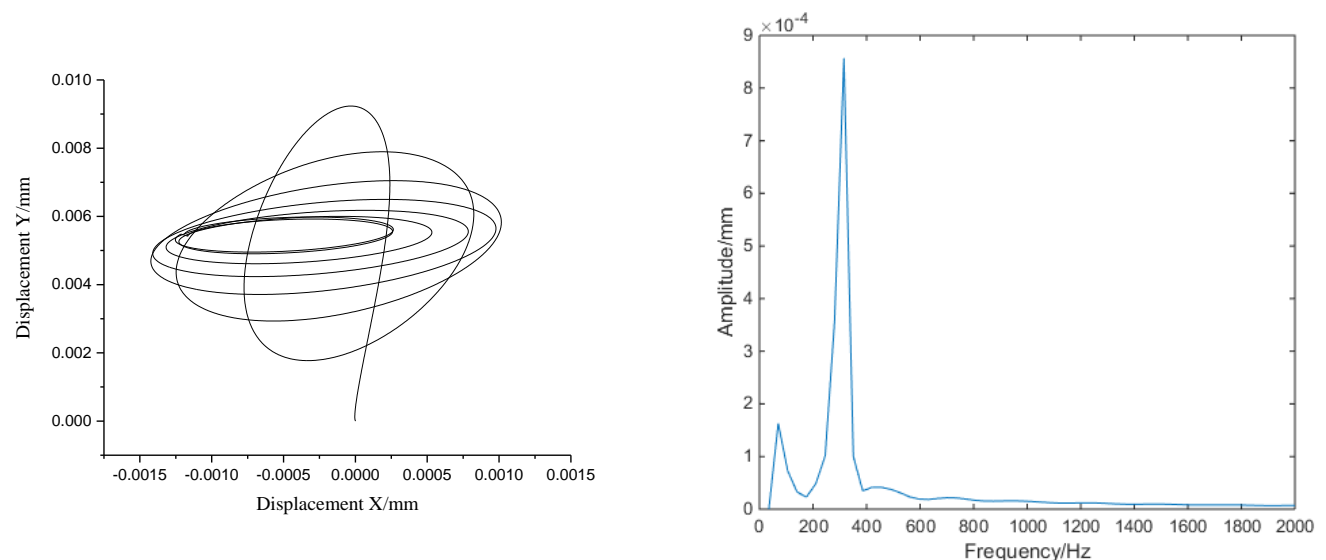

Figure 11. 20000r/min axis trajectory diagram and spectrogram
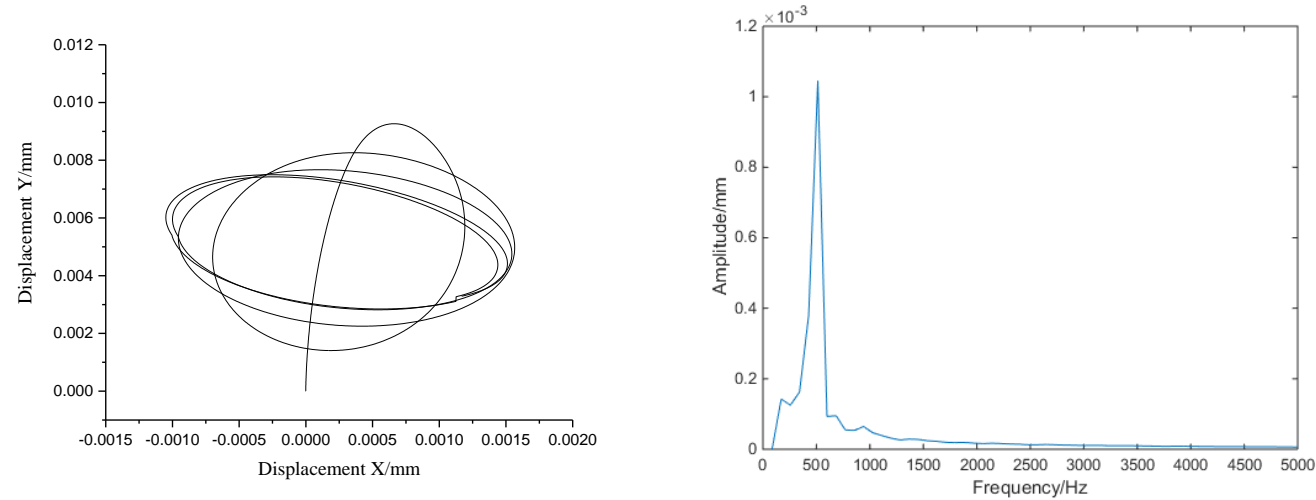

Figure 12. 30000r/min axis trajectory diagram and spectrogram 

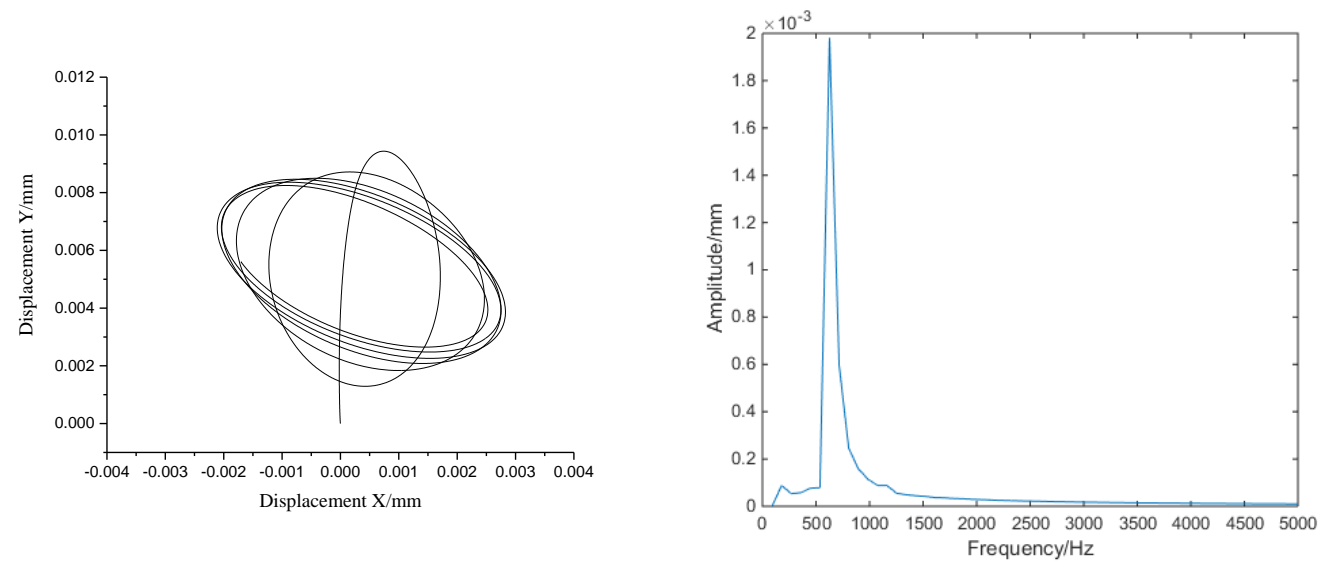

Figure 13. 40000r/min axis trajectory diagram and spectrogram
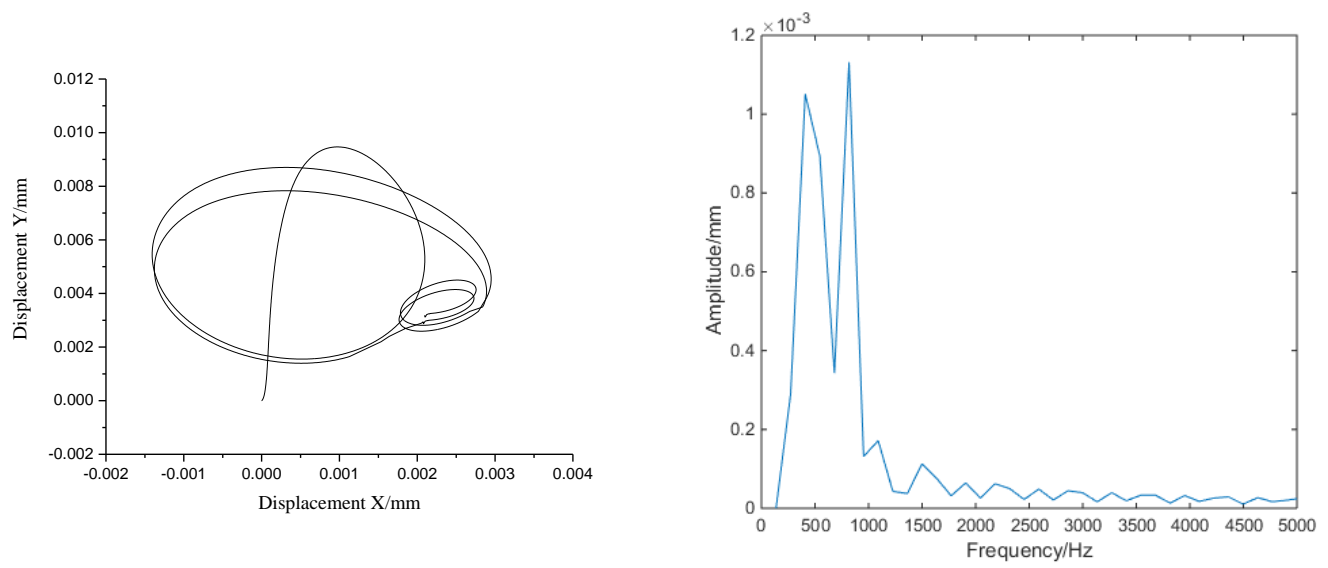

Figure 14. 50000r/min axis trajectory diagram and spectrogram

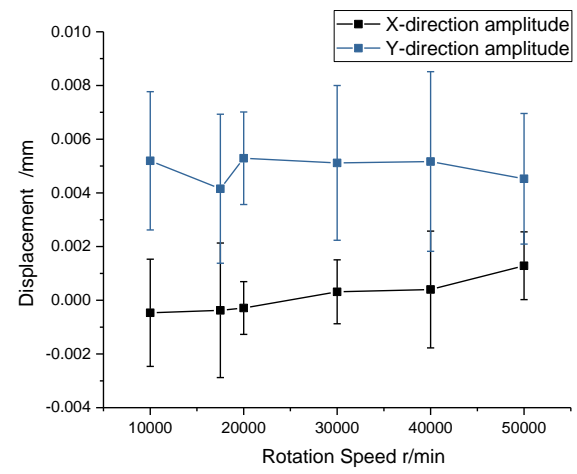

Figure 15. Variations of the amplitude in $\mathrm{x}$ and $\mathrm{y}$ direction with rotation speed

Figure 15 shows the stability characteristics of the bearing was analyzed on the variations of the amplitude at $\mathrm{x}$ and $\mathrm{y}$ direction with respect to rotational speed. From Figure 9 to 11 , when the bearing rotation speed is $10000 \mathrm{r} / \mathrm{min}$, the axis trajectory is the 
standard ellipse. The motion belongs to the same frequency whirl, which is still linear and then decreases. When rotation speed in the $17500 \mathrm{r} / \mathrm{min}$, the corresponding spectrogram shows the maximum value of the working frequency amplitude. And the first-order critical speed of the system is appeared, at this time the bearing is still stable. As can be seen from Figures 12 to 14 , when the rotation speed is gradually increased from $20000 \mathrm{r} / \mathrm{min}$ to $40000 \mathrm{r} / \mathrm{min}$. The axis trajectory diagram shows that the running state changes from quasi-periodic motion to periodic motion, and the amplitude shows an increasing trend. And the whirl energy of the bearing increases gradually, and the axis trajectory gradually diverges. When the rotation speed reaches $40000 \mathrm{r} / \mathrm{min}$, the vibration of the bearing appears the relatively weak half-frequency and doublefrequency. When the rotation speed increases to $50000 \mathrm{r} / \mathrm{min}$, the half-frequency is obviously enhanced, and the axis trajectory also has obvious half frequency whirl.

\section{Dynamic calculation and stability analysis}

\subsection{Variation of rotation speed on dynamic characteristic coefficients}

When the dynamic pressure gas bearing is running at high speed, the change of the operation parameters (rotation speed, gas supply pressure, external load, disturbance frequency) will cause the change of the flow field inside the gas film, and the characteristics of the gas film will be reconstructed. It will cause the change of the eccentricity, the pressure distribution of the gas film, the nonlinear gas film force, the bearing performance, the dynamic characteristic and the stability ${ }^{21-22}$. Figure 16 shows the variation law of the stiffness and damping of the bearing with the rotation speed.

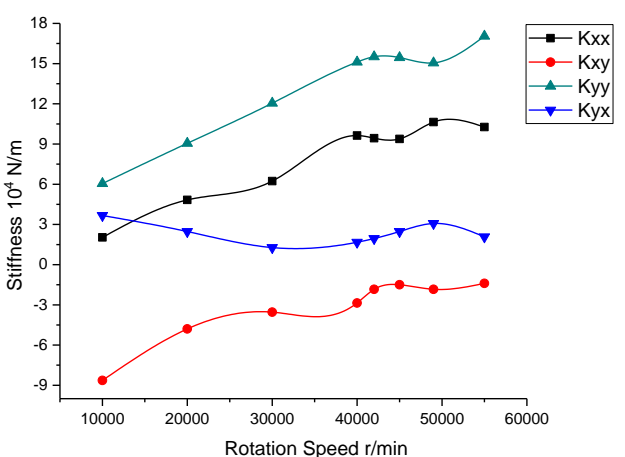

a.

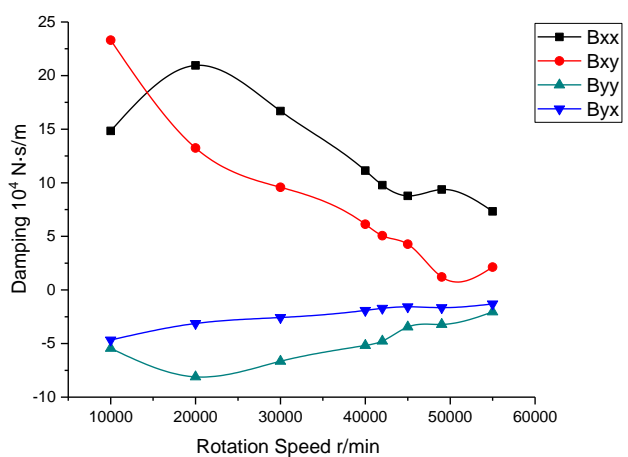

b. 
Figure 16. Variation of rotation speed on stiffness and damping coefficients

In the case of constant structure parameters and the bearing gas supply pressure is $0.2 \mathrm{MPa}$, the rotation speed of the gas bearing increases from $10000 \mathrm{r} / \mathrm{min}$ to 55000 $\mathrm{r} / \mathrm{min}$. The following conclusions can be drawn:

(1) It can be seen from the figure 16a that the direct stiffness coefficient $k_{x x}, k_{y y}$ increases rapidly, and the cross stiffness coefficient $k_{x y}, k_{y x}$ decreases gradually. Figure $16 \mathrm{~b}$ shows that the direct damping coefficient increases gradually, and reaches the maximum when the rotation speed is around $20000 \mathrm{r} / \mathrm{min}$. The cross damping coefficient $b_{x y}$ decreases rapidly, while $b_{y x}$ decreases slowly. In the vicinity of 20000 $\mathrm{r} / \mathrm{min}$, a system natural first-order critical speed of $17500 \mathrm{r} / \mathrm{min}$ appeared, and the corresponding spectrogram shows the maximum value of the working frequency amplitude. Below this speed, the axis trajectory diagrams shows linear stability period 1 motion.

(2) When the rotation speed is increased to $40000 \mathrm{r} / \mathrm{min}$, the direct stiffness coefficient $k_{x x} 、 k_{y y}$ is unchanged. But the cross stiffness coefficient $k_{x y} 、 k_{y x}$ gradually increased and the damping coefficient trend is basically unchanged. When the rotation speed is increased to $45000 \mathrm{r} / \mathrm{min}$, the spectrogram shows the phenomenon of half frequency whirl, and the axis trajectory diagrams shows non-linear stability period 2 motion. It shows that the increase of cross stiffness coefficient leads to the gas film whirl force is greater than the damping, and the gas film whirl occurs.

(3) When the rotation speed is between $40000 \mathrm{r} / \mathrm{min}$ and $50000 \mathrm{r} / \mathrm{min}$, the stiffness and damping changed unregularly. The direct stiffness coefficient $k_{x x}$ gradual from decrease to increase, $k_{y y}$ from increase to decrease. The direct damping coefficient $b_{x x} 、 b_{y y}$ from gradually decreased to gradually increased, and the cross damping coefficient $b_{x y}$ decreases significantly. In this process, the period 2 motion and the chaotic trajectory appears repeatedly.

(4) When the rotation speed reaches $55000 \mathrm{r} / \mathrm{min}$, the direct stiffness coefficient $k_{x x}$ from increase to decrease, while the $k_{y y}$ rapidly increases. The cross stiffness coefficient $k_{x y}, k_{\mathrm{y} x}$ appear downward trend. The direct damping coefficient $b_{x x}, b_{y y}$ changed from increased to rapidly decreased, and the cross damping $b_{x y}, b_{y x}$ decreased to almost zero. 


\subsection{Variation of gas supply pressure on dynamic characteristic coefficients}

Under the condition of $20000 \mathrm{r} / \mathrm{min}$ rotation speed, the variation of gas supply pressure on stiffness and damping coefficients were simulated by changing the gas supply pressure.
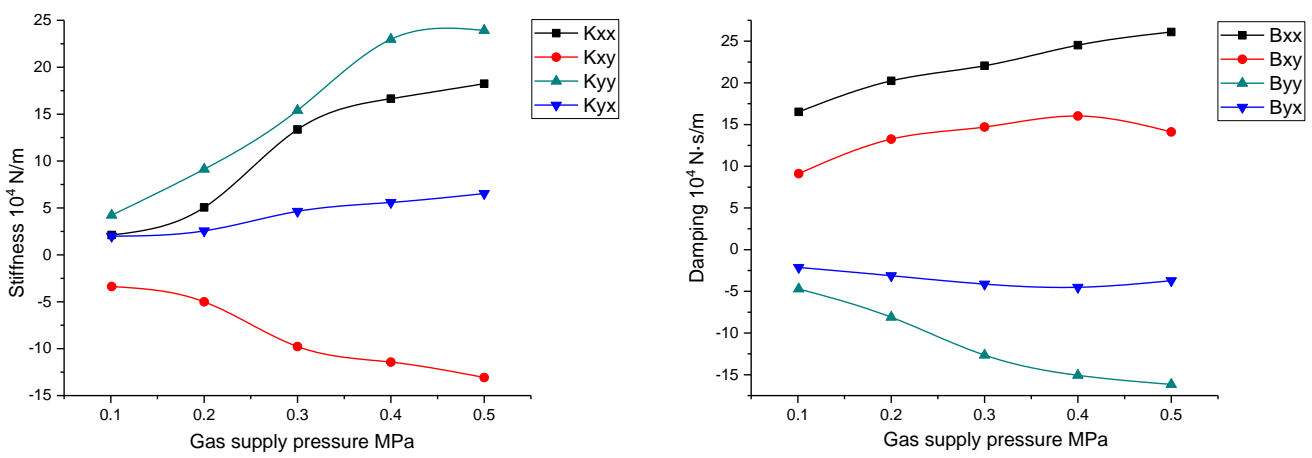

Figure 17. Variation of gas supply pressure on stiffness and damping coefficients

As shown in figure 17, with the increasing of gas supply pressure, the direct stiffness coefficients $k_{x x}$ and $k_{y y}$ direction are the same and the trend is increasing. At the same time, the cross stiffness coefficients $k_{x y}$ and $k_{y x}$ gradually increase, but the trend is slow. When the gas supply pressure exceeds $0.4 \mathrm{MPa}$, the increasing trend of direct stiffness coefficients are slowed down. With the increasing of gas supply pressure, the direct damping coefficients $b_{x x}$ and $b_{y y}$ direction are the opposite and the trend is increasing. The cross damping coefficients $b_{x y}, b_{y x}$ direction opposite and gradually increases, but the trend is slow. When the gas supply pressure exceeds $0.4 \mathrm{MPa}$, the cross damping coefficients $b_{x y}, b_{y x}$ gradually decrease.

When the gas supply pressure is $0.1 \mathrm{MPa}$, the bearing operation is close to the pure dynamic pressure bearing. When the gas supply pressure exceeds $0.4 \mathrm{MPa}$, the bearing operation is close to pure static pressure bearing. The stability of the bearing is continuously improved with the increase of gas supply pressure.

\subsection{Variation of tangential angle on dynamic characteristic coefficients}

The change of the structure parameters of the gas bearing directly changes the geometrical structure of the gas film, thus changing the lubrication characteristics and dynamic characteristics of the gas film during high speed operation. For hybrid gas 
bearings, the main structure parameters are tangential angle, groove width ratio, groove depth ratio, helix angle and slot number. Changing the tangential angle can produce the circumfluence effect to reconstruct the dynamic characteristics of the gas film, which can change the coupling relationship between the natural frequencies of the system and the vortex frequencies of the gas film, and improve the stability of the bearing during high speed operation ${ }^{23-24}$.
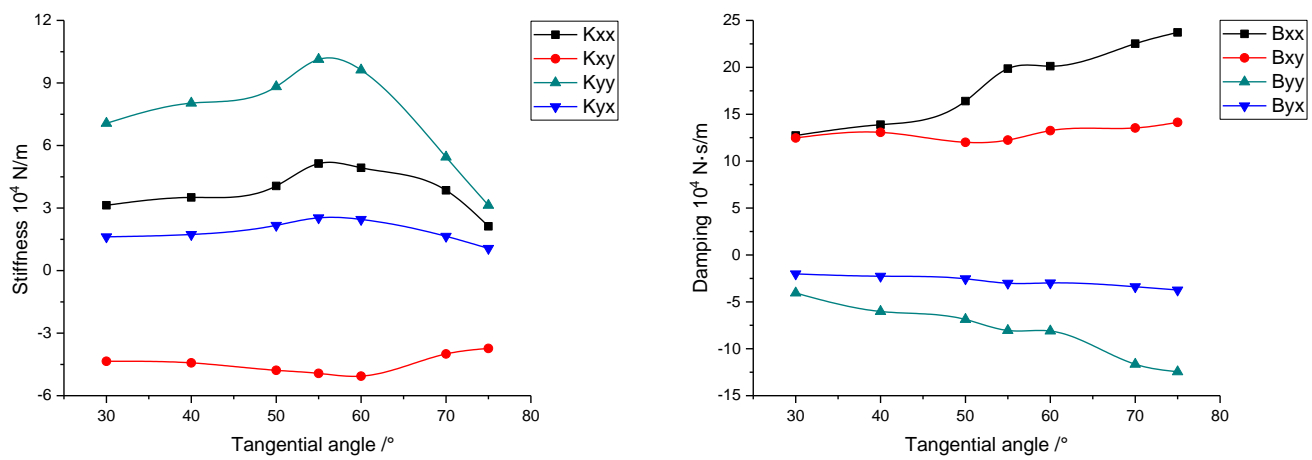

Figure 18. Variation of tangential angle on stiffness and damping coefficients

As shown in Figure 18, with the increase of the tangential angle, the direct stiffness coefficients $k_{x x}$ and $k_{y y}$ of the bearings increase first and then decrease. When the tangential angle exceeds $60^{\circ}$, the direct stiffness coefficient $k_{x x}$ and $k_{y y}$ rapidly decrease. The cross stiffness coefficients $k_{x y}$ and $k_{y x}$ also showed a similar trend, but the trend of change was slow. The stiffness coefficient $k_{y y}$ in the load direction is larger than the stiffness coefficient $k_{x x}$ in the non-load direction. When the tangential angle is $55^{\circ}$, the stiffness of the bearing is the largest. And the damping coefficient $b_{y y}$ in the load direction is smaller than the damping coefficient $b_{x x}$ in the non-load direction. With the increasing of tangential angle, $b_{y y}$ and $b_{x x}$ showed increasing trend, which increased obviously in the $50^{\circ}-60^{\circ}$.

As shown in figures 19, the rotation speed is the 20000r/min axis trajectory diagram, when the tangent angle is $75^{\circ}$ and $30^{\circ}$. 


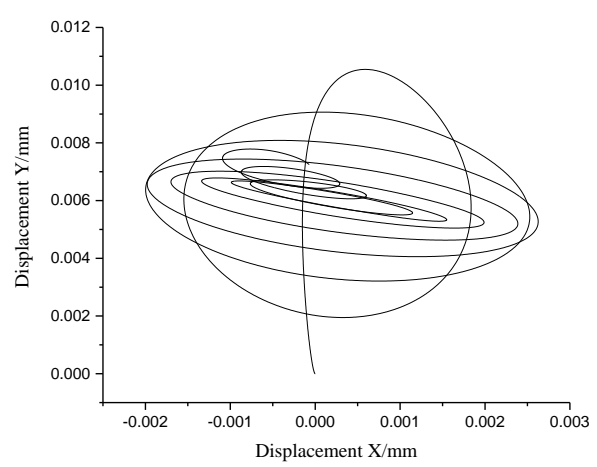

(a) Tangential angle $75^{\circ}$

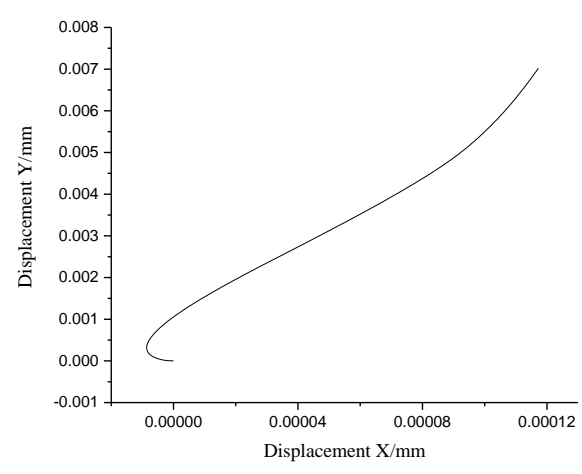

(b) Tangential angle $30^{\circ}$

Figure 19. Axis trajectory diagram

When the tangential Angle is $75^{\circ}$, bearing stiffness is small, but has a larger damping. At this time, the gas film whirl force is smaller than the damping and the whirl energy is decreasing, the axis whirl trajectory is convergent. The increase of damping maintains the whirl stability. When the tangential angle is $30^{\circ}$, bearing stiffness is large, but the damping of the system is very small. Simulation calculations in a very short period of time will be error, resulting in the calculation can not proceed, the axis trajectory as shown in Figure 19b. At this time, the bearing gas film whirl force is greater than the damping, gas film force work to promote the whirl energy continues to increase, which leads to the axis trajectory movement divergence. Therefore, the tangential angle is selected between the $55^{\circ}-60^{\circ}$, which can ensure the bearing gas film has higher stiffness, but also has a larger damping coefficient, to ensure more stable and high-speed operation of the bearings.

\section{Experimental verification}

\subsection{Test principles}

This experimental test system includes high pressure gas source I, bearing test machine II, signal detection system III, data processing system IV, the overall scheme as shown in Figure 20. The equipment 1-6 connected to form a high-pressure gas source I that provides the gas supply pressure of $0.8 \mathrm{MPa}$ and the gas supply flow rate of $2.4 \mathrm{~L} / \mathrm{min}$. The high-pressure gas source I provides high-pressure gas to the bearing testing machine II, a part of which is used as a supporting gas to supply the gas bearing, and the other part is used as a power gas supplying turbine to drive the bearing rotor to rotation. 
The signal detection system III measures the gas film force, vibration displacement, vibration speed, and rotation speed of the gas bearing in the $\mathrm{X}, \mathrm{Y}$, and $\mathrm{Z}$ directions. The data processing system IV processes and calculates test data to obtain the gas film stiffness and damping coefficients.

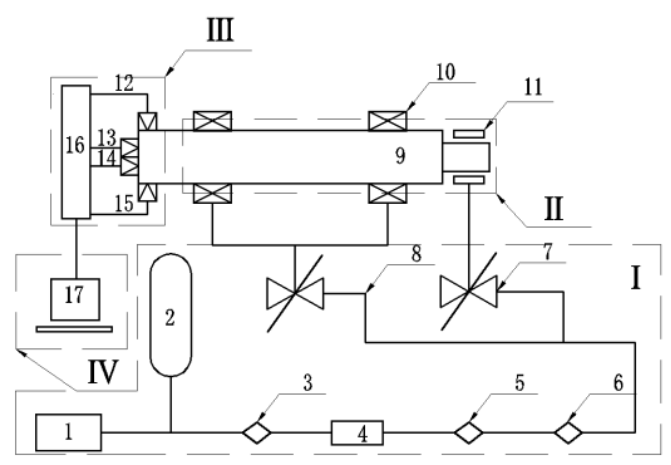

1-Air compressor; 2-Gas storage tank; 3-High temperature freeze drier; 4-Separator filter; 5-Main pipeline filter; 6-Oil removal filter; 7-Turbine valve; 8-Bearing gas supply valve; 9-Bearing rotor; 10-Gas bearing; 11-Turbine; 12, 13, 14- X, Y, Z axis laser displacement sensor; 15-Speed sensor; 16-Data acquisition device; 17-Computer

Figure 20. Overall scheme diagram of test machine

\subsection{Main structure of test machine}

The main structure of bearing test machine is shown in Figure 21. The gas bearing test machine is mainly composed of bearing rotor system, driving turbine, bearing seat and frame. The hemispherical diameter of the bearing testing machine is $15 \mathrm{~mm}$ and the gas film thickness is $10 \mu \mathrm{m}$. The structure parameters are shown in Table 1.

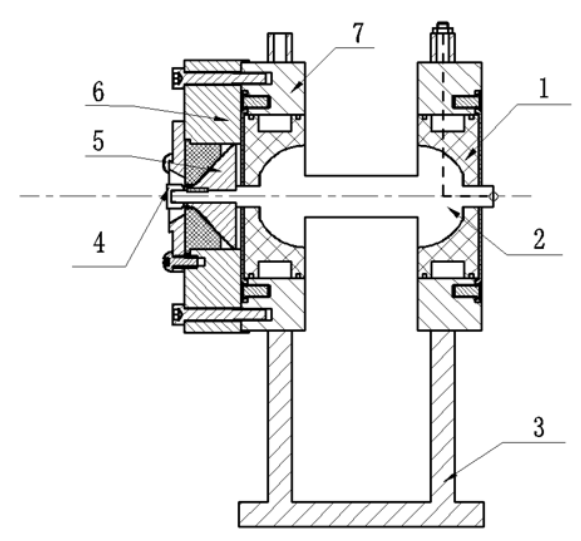


1-Gas bearing; 2-Gas bearing rotor; 3-Frame; 4-Turbine end cover; 5-Turbine; 6-Turbine cover; 7Bearing seat

Figure 21. Main structure of test machine
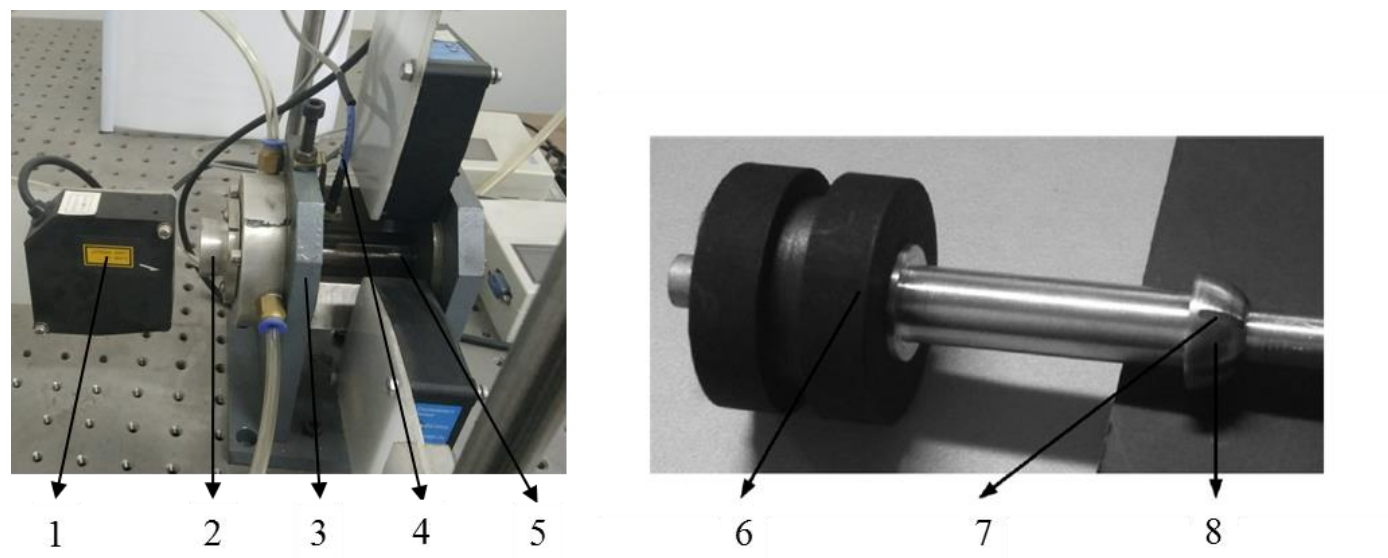

1-Laser displacement sensor; 2-Turbine; 3-Frame; 4-Speed sensor; 5-Gas bearing-rotor system; 6-

Gas bearing; 7-Spiral groove; 8-Rotor

Figure 22. Bearing test machine

Table 1. The design parameters of hybrid gas bearings

\begin{tabular}{cc}
\hline Structure name & Parameter \\
\hline Bearing diameter $\phi_{1}(\mathrm{~mm})$ & 15 \\
Groove depth ratio $\bar{h}$ & 3.6 \\
Groove width ratio $\bar{b}$ & 0.4 \\
The number of grooves $N_{g}$ & 6 \\
Helix angle $\beta\left({ }^{\circ}\right)$ & 70 \\
The average gas film thickness $h_{0}(\mu \mathrm{m})$ & 20 \\
Small hole diameter $\phi_{2}(\mathrm{~mm})$ & 0.2 \\
Gas supply hole row number & 2 \\
Number of gas supply holes & 6 \\
\hline
\end{tabular}

\subsection{Experimental test}

\subsubsection{Bearing rotor critical speed experimental test}

The gas supply pressure of the bearing of the gas bearing test bench was adjusted to $0.2 \mathrm{MPa}$ for experimental testing. The turbine gas supply system was started and the rotor rotation speed smoothly increased during the period 1 of the linear stability. In the initial stage, the rotation speed of the rotor is low, the dynamic pressure effect of the gas film and the rotation inertia of the rotor are small. The pressure fluctuation of the gas supply has a significant effect on the rotor operation, and the rotor axis trajectory is 
blurred. As the rotation speed increases, the rotor vibration frequency caused by the unbalanced quantity gradually approaches the natural frequency of the test machine. Resonance occurs at the first critical speed 17650r/min and the rotor vibration amplitude reaches the maximum value. Across the first critical speed, the rotor speed continues to increase in a certain range, and the rotor vibration amplitude begins to decrease. Rotor rotation inertia and radial stability increase, and the influence of gas supply pressure fluctuation on the rotor operation is reduced. The rotor vibration frequency is strengthened and gradually dominated, and the rotor axis trajectory becomes clear and presents a single ellipse. The data processing system extracts the test data of rotor speed of $9600 \mathrm{r} / \mathrm{min}, 17500 \mathrm{r} / \mathrm{min}$, and $20300 \mathrm{r} / \mathrm{min}$, and draws the axis trajectory and spectrogram of the rotor, as shown in Figure 23-25.
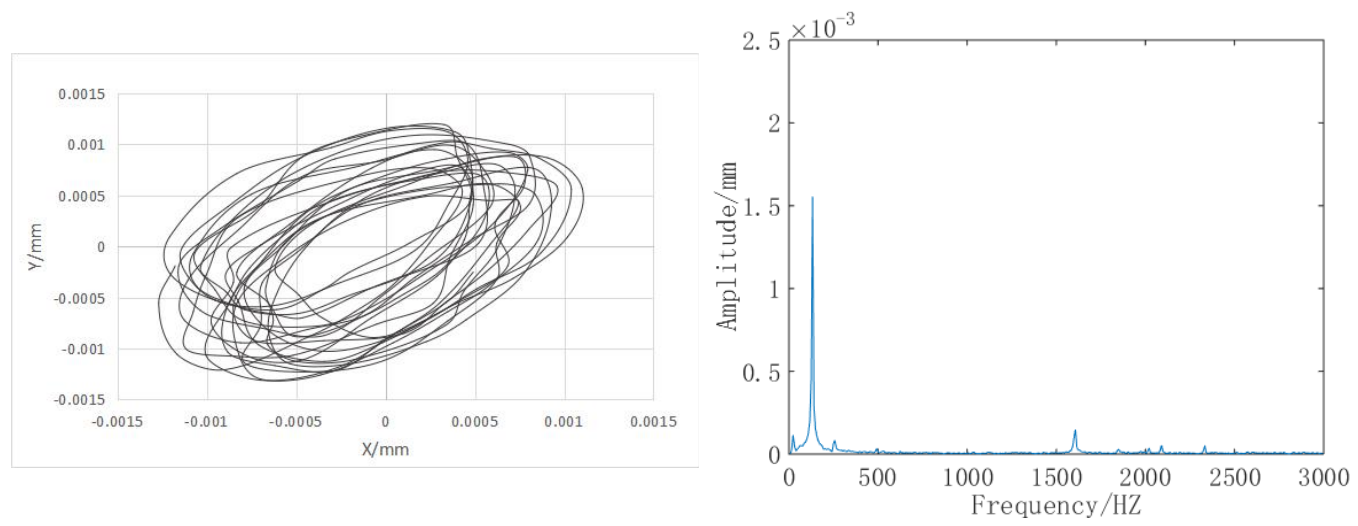

Figure 23. $9600 \mathrm{r} / \mathrm{min}$ axis trajectory diagram and spectrogram of test results
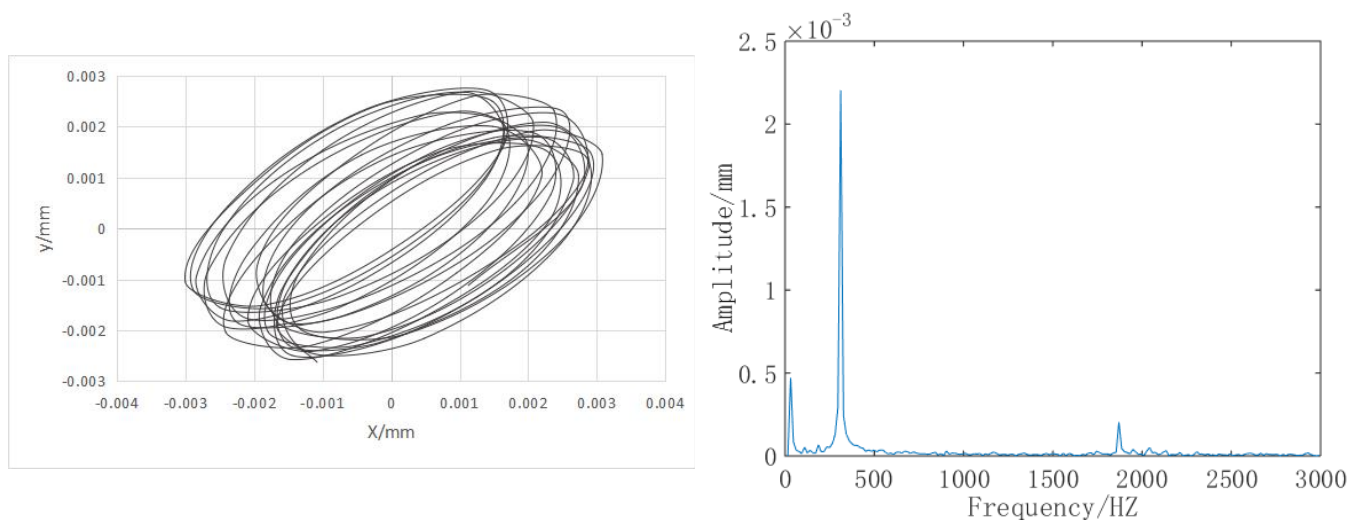

Figure 24. $17650 \mathrm{r} / \mathrm{min}$ axis trajectory diagram and spectrogram of test results 

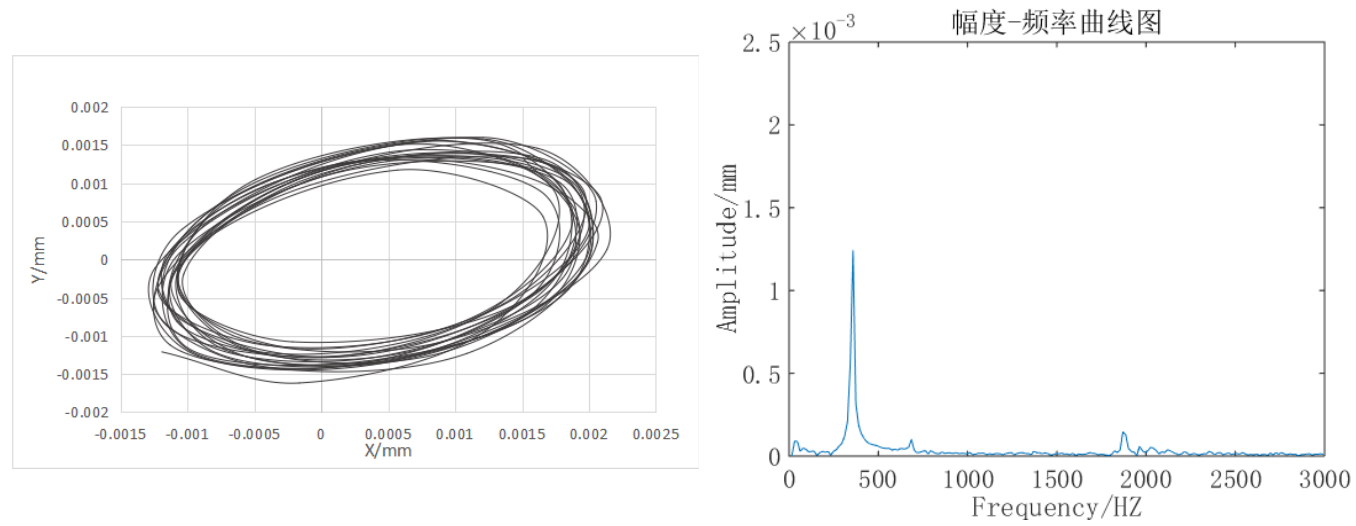

Figure $25.20300 \mathrm{r} / \mathrm{min}$ axis trajectory diagram and spectrogram of test results

\subsubsection{Stiffness and damping test}

When the rotor of a gas bearing is running, the rotor deviates from the steady state of equilibrium and moves around it. The relation expression of the displacement disturbance and the velocity disturbance and the increment of the gas film force is expressed, combined with the bearing rotor the system dynamics equation calculates the stiffness and damping coefficients of the gas film.

When the bearing rotor axis moves slightly in a static equilibrium position, the linear increment of the gas film force is expressed as:

$$
\left\{\begin{array}{l}
\Delta F_{x}=F_{x}-F_{x 0}=k_{x x} \Delta x+k_{x y} \Delta y+b_{x x} \Delta \dot{x}+b_{x y} \Delta \dot{y} \\
\Delta F_{y}=F_{y}-F_{y 0}=k_{y x} \Delta x+k_{y y} \Delta y+b_{y x} \Delta \dot{x}+b_{y y} \Delta \dot{y}
\end{array}\right.
$$

When the rotor moves slightly in a static equilibrium position, the rotor center deviates from the static equilibrium position in $\mathrm{x}$ and $\mathrm{y}$ directions. The instantaneous operating parameters are $\Delta x, \Delta y, \Delta \dot{x}, \Delta \dot{y}, \ddot{x}, \ddot{y}$, and the corresponding increment of the gas film force is $\Delta F_{x}, \Delta F_{y}$. The dynamic equations of the bearing rotor system are as follows:

$$
\left\{\begin{array}{l}
m \ddot{x}+\Delta F_{x}=0 \\
m \ddot{y}+\Delta F_{y}=0
\end{array}\right.
$$

The stiffness damping model equation of the gas film can be obtained by simultaneous equation (7) and equation (8). 
Solving the gas film stiffness and damping coefficient of the model equation (9), and the constant coefficients of the model equation must first be obtained. And the constant coefficients $\Delta x, \Delta y, \Delta \dot{x}, \Delta \dot{y}, \ddot{x}, \ddot{y}$ can be obtained by data pretreatment.

To solve for the gas film stiffness and damping coefficient, each equation in Equation (9) must consist of four different equations, where the determinant of the coefficient matrix is nonzero.

During the experiment, the sampling frequency of the data collection system is very high. It is considered that the rotor only undergoes minute movements during the four sampling processes, and the rotor operation state and the gas film force change are small and negligible. Therefore, the preprocessed data of the first to fourth sampling in the MYSQL database are substituted into the model matrix equation 9 for calculation, and the stiffness and damping coefficient of the gas film at the fourth sampling can be obtained. According to the above method, the Matlab program for the stiffness and damping coefficient of the gas film is compiled, and the rolling iteration method is used to process and calculate the test data, and the stiffness and damping coefficient of the gas film of the bearing rotor is obtained.

$$
\left[\begin{array}{cccc}
\Delta x_{n-3} & \Delta y_{n-3} & \Delta \dot{x}_{n-3} & \Delta \dot{y}_{n-3} \\
\Delta x_{n-2} & \Delta y_{n-2} & \Delta \dot{x}_{n-2} & \Delta \dot{y}_{n-2} \\
\Delta x_{n-1} & \Delta y_{n-1} & \Delta \dot{x}_{n-1} & \Delta \dot{y}_{n-1} \\
\Delta x_{n} & \Delta y_{n} & \Delta \dot{x}_{n} & \Delta \dot{y}_{n}
\end{array}\right] \times\left[\begin{array}{cc}
k x x_{n} & k y x_{n} \\
k x y_{n} & k y y_{n} \\
b x x_{n} & b y x_{n} \\
b x y_{n} & b y y_{n}
\end{array}\right]=\left[\begin{array}{cc}
m \ddot{x}_{n-3} & m \ddot{y}_{n-3} \\
m \ddot{x}_{n-2} & m \ddot{y}_{n-2} \\
m \ddot{x}_{n-1} & m \ddot{y}_{n-1} \\
m \ddot{x}_{n} & m \ddot{y}_{n}
\end{array}\right]
$$

The bearing gas pressure of the gas bearing test bench is adjusted to $0.3 \mathrm{Mpa}$ for test. The data processing system extracts the test data of the gas film force, vibration displacement, vibration speed and rotation speed of the rotor of $10000 \mathrm{r} / \mathrm{min}, 20000 \mathrm{r} / \mathrm{min}$, 30000r/min, 40000r/min, 50000r/min and 55000r/min respectively. According to equations (10), the gas film stiffness and damping Matlab program is used to process and calculate the experimental data, and the stiffness and damping coefficient of the gas film are obtained. Finally, the stiffness and damping coefficients with an eccentricity ratio of 0.3 is extracted, and the stiffness and damping coefficient of the bearing are 
obtained by the average value. The relationship between the gas film stiffness damping

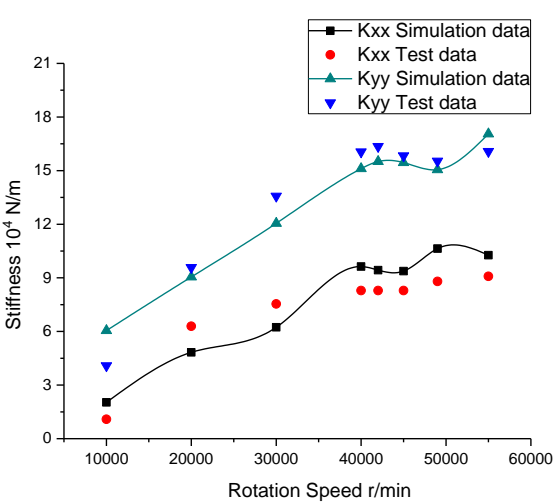

a. Direct stiffness

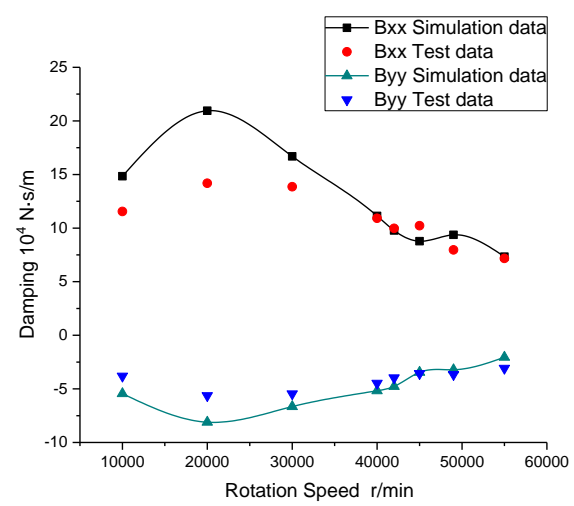

c. Direct damping

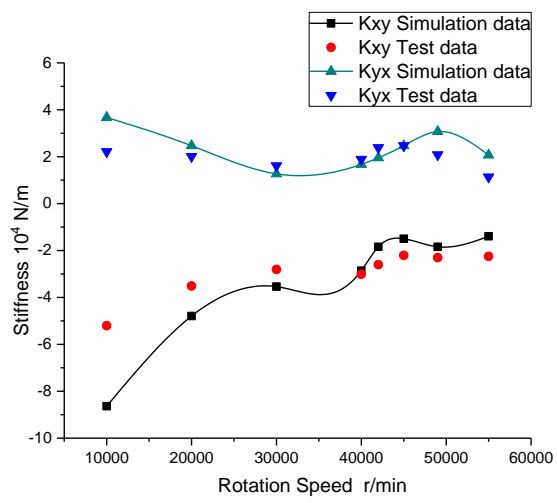

b. Cross stiffness

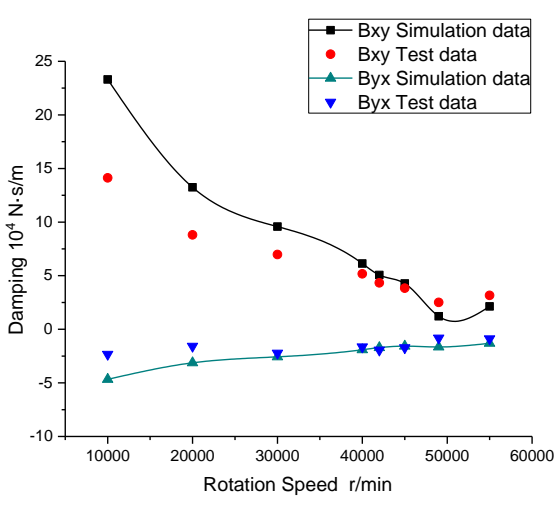

d. Cross damping

Figure 26. Comparison of simulation results and test results

The results show that the comparing the results of simulation and experimental data, the change trends of the two are consistent, and there is a certain error between the simulation results and the experimental results. The assumption of some boundary conditions is more ideal when simulating simulation calculation. And the results are related to the solver model, the grid quality, the boundary conditions and the dynamic grid model, and the parameter settings. The actual rotor mass unbalance, bearing machining error, shafting assembly error and other factors have a great influence on the test results. Therefore, there are some errors in simulation and experimental data. On the whole, the test data is consistent with the simulation results. The correctness and validity of the simulation method of 6 DOF passive grid based on FLUENT software are verified. 


\section{Conclusion}

(1) Based on FLUENT, the pressure distribution on the gas film grid point of the hybrid gas bearings was calculated by using the 6 DOF passive grid method, which can simulate the lubrication characteristics of the gas film transient flow field accurately. Hybrid gas bearings with static pressure and dynamic pressure nonlinear coupling effect, which makes the pressure distribution in the circumferential direction more uniform and the load distribution more reasonable. Dynamic and static pressure coupling effect can not only enhance the bearing performance of the gas film, but also optimize the dynamic characteristics. It can effectively restrain the generation of whirl and oscillation, and improve the stability of high speed operation.

(2) Different rotation speed and gas supply pressure cause the change of flow field inside the gas film, which will change the pressure distribution, nonlinear gas film force, stiffness and damping coefficients during the operation of the gas film. The analysis shows that the variation of cross stiffness is the main reason of the half frequency whirl caused by the gas film whirl force greater than the gas film damping. Increasing the gas supply pressure of hybrid gas bearings will change the characteristics of the gas film flow field and improve the stiffness and damping during operation. It can effectively restrain the generation of whirl, and improve the stability.

(3) For hybrid gas bearings, changing the tangential angle can produce the circumfluence phenomenon to reconstruct the dynamic characteristics of the gas film. It can change the coupling relationship between the natural frequencies of the system and the whirl frequencies of the gas film. For hybrid gas bearings, the tangential angle between $55^{\circ}-60^{\circ}$, both to ensure the gas film have greater stiffness, while also have a more reasonable damping characteristics, to ensure the bearing operated high-speed and smoothly.

\section{Acknowledgement}

This work is supported by National Natural Science Foundation of China (Grant no: 51475142), and Program for Innovative Research Team (in Science and Technology) in University of Henan Province (Grant no: 13IRTSTHN025). 


\section{References}

1. Ma WQ, Yu HC, Sun A (2010) Research situation of gas-bearing/rotor system. Lubrication Engineering $35 \quad$ (6):121-125. DOI: $10.3969 /$ j.issn.02540150.2010.06.029

2. Zhang WM, Zhou JB, Meng G (2011) Performance and stability analysis of gaslubricated journal bearings in MEMS. Tribol Int 44 (7-8):887-897. https://doi.org/10.1016/j.triboint.2011.03.004

3. Lu ZW, Wei MM (2014) Numerical simulation and experimental study of the static performance of the aerodynamic bearings. Tribology 34 (1):36-42. DOI:10.16078/j.tribology.2014.01.010

4. Wang B, Sun Y, Ding Q (2016) Dynamic characteristics of the herringbone groove gas journal bearings: numerical simulations. Shock Vib 2016,(2016-12-12) 2016:113. http://dx.doi.org/10.1155/2016/8743016

5. Rashidi R, Mohammadi AK, Nejad FB (2010) Bifurcation and nonlinear dynamic analysis of a rigid rotor supported by two-lobe noncircular gas-lubricated journal bearing system. Nonlinear Dyn 61 (4):783-802. https://doi.org/10.1007/s11071010-9687-5

6. San Andrés L (2006) Hybrid flexure pivot-tilting pad gas bearings: analysis and $\begin{array}{llllll}\text { experimental validation. } \mathrm{J} \text { Tribol-T ASME } 128 & \text { (3):551-558. DOI: }\end{array}$ $10.1115 / 1.2194918$

7. Yu P, Chen X, Wang X, Jiang W (2015) Frequency-dependent nonlinear dynamic stiffness of aerostatic bearings subjected to external perturbations. Int J Precis Eng Manuf 16 (8):1771-1777. https://doi.org/10.1007/s12541-015-0232-9

8. Jia C, Pang H, Ma W, Qiu M (2016) Dynamic stability prediction of spherical spiral groove hybrid gas bearings rotor system. J Tribol-T ASME 139 (2):021701021701-021713. DOI: $10.1115 / 1.4033453$

9. Li Q, Zhang S, Ma L, Xu W, Zheng S (2017) Stiffness and damping coefficients for journal bearing using the 3D transient flow calculation. J Mech Sci Technol 31 (5):2083-2091. https://doi.org/10.1007/s12206-017-0405-9

10. Jia C, Pang H, Ma W, Qiu M (2017) Analysis of dynamic characteristics and stability prediction of gas bearings. Ind Lubr Tribol 69 (2):123-130. http://dx.doi.org/10.1108/ILT-09-2015-0134

11. Han DJ, Yang JF, Chen CT, Zhao C (2014) Experimental research for effects of bearing supply gas pressure on aerostatic bearing-rotor system dynamic characteristics. Journal of Propulsion Technology 35(9):1265-1270. DOI: 10.13675/j.cnki.tjjs.2014.09.017

12. Zhang Y, Hei D, Lü Y, Norbert M (2014) Bifurcation and chaos analysis of nonlinear rotor system with axial-grooved gas-lubricated journal bearing support. Chin J Mech Eng 27 (2):358-368. https://doi.org/10.3901/CJME.2014.02.358

13. Zhang GH, Liu ZS (2011) Performance analysis of membrane restrictor hybrid journal gas bearings. Journal of Mechanical Engineering 47 (3):73-80. DOI: 10.3901/JME.2011.03.073

14. Rudloff L, Arghir M, Bonneau O, Guingo S, Chemla G, Renard E (2012) Experimental analysis of the dynamic characteristics of a hybrid aerostatic bearing. J Eng Gas Turbines Power-Trans ASME 134(8):082503-082503-8. DOI: $10.1115 / 1.4006060$

15. Miyatake M, Yoshimoto S (2010) Numerical investigation of static and dynamic characteristics of aerostatic thrust bearings with small feed holes. Tribol Int 43 (8):1353-1359. https://doi.org/10.1016/j.triboint.2010.01.002

16. Nishio U, Somaya K, Yoshimoto S (2011) Numerical calculation and experimental 
verification of static and dynamic characteristics of aerostatic thrust bearings with small feedholes. Tribol Int 44 (12):1790-1795. https://doi.org/10.1016/j.triboint.2011.07.004

17. Yu HC, Ma WQ, Wang ZW, Xu LF (2009) Research on static characteristics of radial aerostatic bearings based on FLUENT. Lubrication Engineering 34 (12):7781. DOI: $10.3969 /$ j.issn.0254-0150.2009.12.020

18. Wang CC, Hung JP (2016) Theoretical and bifurcation analysis of a flexible rotor supported by gas-lubricated bearing system with porous bushing. J Vibroeng 18(3):1934-1940. https://doi.org/10.21595/jve.2015.16752

19. Wang CC (2016) Non-periodic and chaotic response of three-multilobe air bearing system. Appl Math Model 47:859-871. https://doi.org/10.1016/j.apm.2016.08.014

20. Lu Y, Zhang Y, Shi X, Wang W, Yu L (2012) Nonlinear dynamic analysis of a rotor system with fixed-tilting-pad self-acting gas-lubricated bearings support. Nonlinear Dyn 69 (3):877-890. https://doi.org/10.1007/s11071-011-0310-1

21. Chen Y, Chiu C, Cheng Y (2010) Influences of operational conditions and geometric parameters on the stiffness of aerostatic journal bearings. Precis Eng 34 (4):722-734. https://doi.org/10.1016/j.precisioneng.2010.04.001

22. Xu FC, Liu ZS, Ma RX, Huang FL (2014) Dynamic performance tests of bumptype gas foil journal bearing-rotor system in start-up and shut-down procedures. Journal of Aerospace Power 29 (1):216-224. DOI: 10.13224/j.cnki.jasp.2014.01.028

23. Hou Y, Xiong LY, Wang BC, Chen CZ (2004) The experimental study of rubber rings support journal gas bearing with orifices of tangential supply. Lubrication Engineering (5):39-40. DOI: 10.3969/j.issn.0254-0150.2004.05.014

24. Yu HC, Ma WQ, Wang ZW, Xu LF (2010) CFD Research on aerostatic bearing with tangential supply holes. Advanced Materials Research 97-101:2021-2026. http://dx.doi.org/10.4028/www.scientific.net/AMR.97-101.2021 
2019-01-03

Flow field calculation and dynamic characteristic analysis of spherical hybrid gas bearings based on passive grid

Jia, Chenhui

Springer

Chenhui Jia, Zhiwu Cui, Shijun Guo, et al., Flow field calculation and dynamic characteristic analysis of spherical hybrid gas bearings based on passive grid. Journal of the Brazilian Society of Mechanical Sciences and Engineering, Volume 41, January 2019, Article 56 https://doi.org/10.1007/s40430-018-1538-1

Downloaded from Cranfield Library Services E-Repository 